Protestantismo em Revista é licenciada sob uma Licença Creative Commons.

http://dx.doi.org/10.22351/nepp.v44i2.3774

\title{
Com a palavra, os jovens: religião, espiritualidade, cultura e globalização
}

\author{
The youngsters have the word: \\ religion, spirituality, culture and globalization
}

Danilo Marques da Silva Godinho*
Cíntia de Sousa Carvalho**
Solange Jobim e Souza

\begin{abstract}
Resumo
Este trabalho, de cunho qualitativo, teve como objetivo pensar as diversas formas de elaboração e expressão do religioso entre os jovens contemporâneos. Levando em consideração que este momento histórico se caracteriza por uma fragmentação, expansão, divulgação e profusão do religioso pelo mundo, constata-se que a época atual é marcada pela manifestação de um sincretismo religioso que nos interessa compreender e investigar. A partir daí surgem questões como: Qual seria então o significado das manifestações religiosas diversas? Como os jovens justificam suas crenças? Em que medida as práticas religiosas estão submetidas às estratégias da cultura massificada? Em que contexto as práticas religiosas podem ser compreendidas como modos de organização social com intenções políticas definidas em função de uma coletividade? Assim, por meio de "oficinas de debate", os jovens entrevistados puderam se posicionar em relação às questões anteriormente mencionadas. Com este trabalho, concluiu-se que, para os jovens, há uma diferença entre a noção de religião e a noção de espiritualidade, sendo esta última representante de uma experiência de transcendência que não necessariamente depende da mediação institucional. Além disso, os jovens entendem que o contexto de globalização produz impactos na dimensão religiosa, produzindo extremo fechamento de algumas religiões ou a abertura de discursos religiosos mais sincréticos.
\end{abstract}

Palavras-chave

Religião. Espiritualidade. Cultura. Globalização. Juventude.

[Texto recebido em janeiro de 2018 e aceito em julho de 2018, com base na avaliação cega por pares realizada por pareceristas ad hoc]

* Psicólogo. Doutor em Psicologia Clínica (PUC/RJ). Docente Efetivo do Centro Universitário de Mineiros (UNIFIMES). Mineiros/GO/Brasil. E-mail: danilogodinho@fimes.edu.br

** Psicóloga. Doutora em Psicologia Clínica (PUC/RJ). Docente Efetiva do Centro Universitário de Mineiros (UNIFIMES). Mineiros/GO/Brasil. E-mail: cintia@fimes.edu.br

*** Professora Doutora do Departamento de Psicologia da Pontifícia Universidade Católica do Rio de Janeiro. Rio de Janeiro/RJ/Brasil. E-mail: soljobim@puc-rio.br 


\begin{abstract}
This work, with a qualitative approach, had as a goal to think the different ways of religious elaboration and expression among the contemporary youngsters. Taking into account that this historical moment is characterized by a fragmentation, expansion, and profusion of the religious through the world, it is assumed that the current moment is noticed by the manifestation of a religious syncretism, that is in our interest to understand and investigate. From this point, questions arise, such as: What would be the meaning of the different religious manifestations? How the youngsters justify their believes? In what measure the religious practices are submitted to the strategies of a massified culture? In which context the religious practices can be understood as means of social organization with defined political intentions regarding the collectivity? So, through "debate workshops" the interviewed youngsters were able to position themselves towards the previously mentioned questions.With this work, it was possible to come to a conclusion that, for the youngsters, there is a difference between notions of religion and notions of spirituality, being this last one the representation of an experiment of transcendence that does not necessarily depends on an institutional mediation. More than that, the youngsters understand that the globalization context creates impact in the religious dimension, producing the closure of some religions or the appearance of more syncretic religious speeches.
\end{abstract}

\title{
Keywords
}

Religion. Spirituality. Culture. Globalization. Youth.

\section{Introdução}

"A juventude que faz profissão de fé em si mesma significa uma religião que ainda não existe".

(Walter Benjamin)

O trabalho de campo em questão tem como objetivo pensar as diversas formas de elaboração e expressão do religioso entre os jovens contemporâneos. Assim, buscamos compreender como estes sujeitos constroem sentidos para sua espiritualidade, bem como investigar de que modo as práticas religiosas dialogam com a cultura de massa globalizada. Assim, foram realizadas "oficinas de debate", de forma que os jovens pudessem se posicionar frente às questões levantadas.

Ao analisar autores que refletem sobre o tema da religião a partir de uma perspectiva sócio-histórica, tais como Jean-Pierre Vernant ${ }^{1}$ e Peter Berger, ${ }^{2}$ constata-se que a relação do homem com o sagrado é antiga e acompanha o ser humano ao longo de sua história. De acordo com Vernant, a religião é um combustível que movimenta as relações humanas, fato que o faz afirmar que o sagrado e o social devem ser estudados juntos,

VERNANT, J. P. Para que servem as religiões. Religião e Sociedade, v. 9, p. 65-70, 1983.

BERGER, P. O dossel sagrado. São Paulo: Paulinas, 1985. 
retomando como exemplo a Grécia antiga. Em tal sociedade, o sagrado fazia parte de todos os aspectos da vida comum, irrigando, portanto, todo o corpo social.

Para Vernant, ${ }^{3}$ a religião é um sistema simbólico capaz de afirmar nossa humanidade, distanciando-nos dos outros animais, pois é um discurso que auxilia o ser humano a produzir um sentido para sua existência e produzir um mundo em que seja possível viver consigo mesmo e em comunidade. Assim, conclui que a religião é aspecto inexorável da condição humana, ainda que, em muitos momentos da história, ela se mascare como irreligião.

Já para Berger, 4 a religião representa na sociedade o nomos mais elevado, o mais eficaz instrumento para garantir alguma ordem na luta contra a iminência do caos. É, portanto, capaz de atribuir sentido à vida mesmo em face da morte, representando com isso a legitimação suprema das instituições. Enfim, o autor entende que construir o mundo é construir um sistema que faça sentido e, a religião, surge como um discurso que ajuda a organizar este sistema. Os autores acima citados nos auxiliam a justificar a relevância deste estudo, no sentido de podermos compreender como os sujeitos, no tempo presente, estão construindo certa relação com sua espiritualidade. ${ }^{5}$

\section{Estratégias metodológicas}

A pesquisa em questão assumiu a proposta de ouvir os jovens sobre os modos como se apropriam da dimensão da fé e analisou a maneira como se expressam sobre esta questão, confrontando pontos de vista. Na medida em que entendemos a relação da juventude com a religião como um dos aspectos da experiência humana que participa intensamente da constituição da subjetividade, atravessando épocas, culturas e espaços sociais distintos, nosso interesse foi o de explicitar o nível de profundidade com que os jovens de hoje, dependendo do contexto socioeconômico e cultural que frequentam, são capazes de expressar sua compreensão desta experiência, transformando-a em atitudes na vida.

Assim, esta pesquisa foi realizada com 16 jovens universitários - e duas universidades distantes da cidade do Rio de Janeiro/RJ -, de faixa etária entre 18 e 29 anos. As duas entrevistas coletivas, que contaram com 08 jovens cada, foram realizadas num formato de "oficinas de debate", com cerca de 1 hora e 30 minutos de duração. Neste espaço, os jovens puderam conversar e debater sobre o tema em questão, discussão que foi mediada pelos pesquisadores.

\footnotetext{
VERNANT, 1983.

BERGER, 1985.

O estudo da juventude, tendo como foco a religião, surgiu da experiência do pesquisador Danilo M. da S. Godinho como bolsista PIBIC-CNPq, a partir da pesquisa intitulada "Juventude e Religião: Modos de Subjetivação na Contemporaneidade". Este estudo originou sua monografia (GODINHO, 2007) e um artigo (GODINHO, 2014).
} 
Os depoimentos foram filmados, transcritos e os discursos dos jovens foram analisados com o objetivo de se colocar em destaque os principais temas que foram surgindo a partir de suas falas. As temáticas foram discutidas à luz do instrumental teórico e o objetivo desta costura foi o de compreender como as discussões levantadas pelos autores se atualizam nas falas dos jovens contemporâneos.

O compromisso de deixá-los falar, apreciando a maneira singular com que defendem seus pontos de vista, colocou em ação a noção de que a escuta do Outro constitui aspecto que participa da formação subjetiva de cada um de nós, além de proporcionar-lhes campo de debate para um confronto discursivo, podendo alargar no bojo do encontro coletivo suas convicções acerca do tema da religião. Desta forma, trabalhamos com a noção oferecida por Bakhtin, ${ }^{6}$ de que o Outro constitui aspecto do si mesmo, sendo a formação subjetiva de cada um de nós perpassada pelos muitos outros com os quais nos deparamos ao longo da vida.

Esta é uma perspectiva do sujeito enquanto ser que expressa uma totalidade. Ainda que fale de um lugar específico, dotado de peculiaridades, é possível encontrarmos uma universalidade dentro de toda a diversidade humana, exposta nos diferentes gêneros discursivos. Cada sujeito não expressa palavras descoladas do interesse da comunidade como um todo, mas ao contrário disso, em toda a forma de expressão comunicativa de qualquer indivíduo que seja, há elementos que remetem a toda a sociedade humana, aproximando-o não apenas daqueles que discursam com ele na situação específica do diálogo, mas com todos os outros que já discutiram determinado tema, ou que ainda podem vir a discutir. Neste sentido, Bakhtin esta pensando a totalidade do mundo, encarnada, em certa medida, em todo e qualquer indivíduo. É como se nós, membros de uma comunidade infinitamente maior e superior, fôssemos cacos de vidro de diferentes tamanhos e formas, mas correspondêssemos a uma mesma estrutura, um mesmo mosaico cujo brilho total e pleno, depende de cada parte.

Deste modo, ao se expressar, o indivíduo fala não apenas de si, mas de um coletivo humano que abarca um todo maior. Esta é a verdadeira inter-relação entre o eu e o outro, o ambiente e o horizonte, descrita pelo autor a partir dos conceitos de dialogismo e alteridade. Nada se esgota em si mesmo; tudo o que por aí vai, atuando e se expressando no mundo, complementa a história humana transbordando-a em vida. Isto porque precisamos trocar com o mundo, buscar o outro para encontrar algo de nós mesmos, e com isso criar nossa própria identidade, formada tanto pela diferença, como pelo que há de comum entre nós. É neste sentido que Bakhtin afirma que "ao abrir-se para o outro, o indivíduo sempre permanece também para si". ${ }^{7}$

BAKHTIN, M. Estética da criação verbal. São Paulo: Martins Fontes, 1992.

BAKHTIN, 1992, p. 394. 
Remetendo esta reflexão teórica para o campo desta pesquisa, nossa metodologia foi balizada pela ideia de interagirmos com os sujeitos da pesquisa buscando os sentidos que estão presentes nos discursos, transformando o significado dado a priori, e abrindo-o para várias possibilidades interpretativas, surgidas nas oficinas de debates. Contrariando o modelo clássico de organização do texto científico, na sessão seguinte apresentaremos os depoimentos dos jovens junto aos dos autores, visto que não percebemos que haja uma hierarquia entre estes discursos. Advindos de lugares de fala distintos, o encontro entre estas vozes, antes, é uma das responsabilidades deste texto científico, que busca ser dialógico e criar novos espaços de fala na escrita.

\section{As oficinas de debates: com a palavra, os jovens Religião e espiritualidade}

A problemática a respeito dos diferentes usos que podem ser feitos da religião aparece nas reflexões de Leonardo Boff, ${ }^{8}$ no seu livro Espiritualidade: Um caminho de transformação. Segundo o autor, institucionalizadas, as religiões correm o risco de se afastar da espiritualidade que lhes deram origem, se corrompendo na busca pela detenção de uma verdade absoluta e pelo poder: "ao substantivar-se e institucionalizar-se em forma de poder, seja sagrado, social, cultural e milenar (como nos estados pontifícios de outrora), as religiões perdem a fonte que as mantém vivas - a espiritualidade". ${ }^{9}$

O que Boff chama de espiritualidade, distinguindo-a da religião, diz respeito à experiência singular de cada sujeito, a uma capacidade de autotranscendência do ser humano que independe de rituais, celebrações ou dogmas de determinada estrutura de pensamento religioso. As instituições são "água canalizada", porém, não podem ser confundidas com a fonte de onde a "água cristalina" parte, que é a essência mesma da espiritualidade. E é neste sentido que o autor afirma:

Há mudanças que são interiores. São verdadeiras transformações alquímicas, capazes de dar um novo sentido à vida ou de abrir novos campos de experiência e de profundidade rumo ao próprio coração e ao mistério de todas as coisas. Não raro, é no âmbito da religião que ocorrem tais mudanças. Mas nem sempre. Hoje a singularidade de nosso tempo reside no fato de que a espiritualidade vem sendo descoberta como dimensão profunda do humano, como o momento necessário para o desabrochar pleno de nossa individuação e como espaço de paz no meio dos conflitos e desolações sociais e existenciais. ${ }^{10}$

8 BOFF, L. Espiritualidade: um caminho de transformação. Rio de Janeiro: Sextante, 2001.

9 BOFF, 2001, p. 28.

10 BOFF, 2001, p. 17. 
Esta noção de espiritualidade pode ser verificada tanto na fala do Gabriel, como no depoimento da Cidiane, ${ }^{11}$ embora estes dois jovens percebam as instituições religiosas de modo muito distinto:

Gabriel: Mas realmente existe essa coisa, existem católicos que não vão à Igreja todo domingo; existem católicos, enfim, que não seguem o catolicismo estrito senso, mas que de alguma forma se conservam católicos, e são esses que talvez mudem a estrutura dogmática da própria Igreja futuramente, ou que estejam mudando, ou que mudam as estruturas dogmáticas de vários sistemas religiosos. Mas enquanto não muda existe essa dicotomia, existem esses opostos, existe essa contradição.

\section{$(\ldots)$}

Cidiane: As pessoas, eu sinto assim, aquelas que realmente vivem a espiritualidade, não são cerceadas em sua liberdade, mas na verdade ela vem ao encontro de necessidades realmente existenciais e profundas do ser.

\section{$(\ldots)$}

Gabriel: Eu também já tive experiências maravilhosas, extasiantes inclusive, que me fizeram mudar totalmente o foco na minha vida, inclusive independente de religião mesmo, uma experiência minha interna, e eu acho que isso é religiosidade; religiosidade é quando você se permite vivenciar ao imperfeito, o absoluto, alguma coisa assim; ou quando a gente se permite ter uma experiência com o todo, que é nossa, que transcende, mas também é imanente. Isso para mim é fundamental, aliás, é o meu ideal de vida.

Essa experiência que não precisa necessariamente de um objeto religioso definido e que é referente a algo que reverbera sentido no mais profundo da singularidade de cada sujeito, acessando uma dimensão impossível de ser esgotada pela via intelectual e que responde antes a uma lógica do sentir que transcende ou transfigura qualquer tentativa de apreensão teórica para dela dar conta na sua totalidade, aparece na fala de muitos jovens entrevistados. Seguem mais exemplos:

Marina: Eu acho que espiritualidade é você acreditar que tem algo para além do material, para além daqui, independente de você ter fé, religião. Você ser espiritualista é você acreditar que tem algo para além daqui. É você deitar na cama à noite e acreditar que tem uma força ali que é sua, uma força que te move. Então você pode ter fé sem ter religião, mas não pode ter religião sem ter fé.

\section{$(\ldots)$}

Rodrigo: Acho que espiritualidade é o principal ponto da fé, porque se você tem espiritualidade você tem fé. Acho que a espiritualidade é você sentir que tem algo de bom, que você acredita 'eu estou protegido, vou chegar em casa bem'; ou seja, é

11 Os nomes aqui utilizados são fictícios. 
estar espiritualmente bem. Se você tem espiritualidade, então você tem a sua fé. A partir da sua espiritualidade você tem a sua fé, independente de você ter religião ou não.

Boff ${ }^{12}$ nos ajuda a pensar tais depoimentos, quando afirma que as religiões são apenas água canalizada não devendo, portanto, serem confundidas com a fonte que lhes dão vida, que é a própria espiritualidade apontada pelos jovens nos depoimentos colocados acima. Os jovens corroboram com a ideia do autor de que a dimensão espiritual é a fonte de onde emerge a fé, com as suas derivações enquanto diferentes expressões religiosas que vemos espalhadas pelo mundo.

Aquilo que encontra em Boff, a desinência de espiritualidade, como algo distinto de um conceito estritamente religioso, e que contempla, deste modo, uma dimensão que ultrapassa os limites de qualquer produto, ou forma de crença religiosa, aparece também como tema recorrente na obra de Walter Benjamin. ${ }^{13}$ A linguagem surge para o autor como o lugar da experiência autêntica e segue uma linha de pensamento em muito semelhante às reflexões de Mikhail Bakhtin (sobre os conceitos de alteridade e dialogismo). Neste sentido, Benjamin trabalha a noção de que a verdadeira experiência é aquela que contempla a existência do outro e que sabe que, sem os outros, não possui contundência. Daí o caráter político que a noção de religiosidade assume no pensamento de Benjamin, pois a experiência que defende é inteiramente impregnada de toda uma ética que a forma, dela participando e representando no fundo o seu cerne, a marca inegável de sua autenticidade.

Religião, política e ética são aspectos inteiramente relacionados entre si na obra de Benjamin. Estes conceitos estão amarrados pela noção de que todos somos corresponsáveis pelo mundo que habitamos, pois o recriamos em cada gesto e postura que assumimos, e em todas as experiências que compartilhamos na vida. Daí a afirmação de Benjamin em seu texto "O ensino de moral", de 1913:

Enquanto hoje em dia multiplicam-se por toda parte as vozes que consideram eticidade e religião como esferas fundamentalmente independentes, a nós parece que apenas na religião, e tão-somente na religião, a vontade pura encontra o seu conteúdo. O cotidiano de uma comunidade ética é plasmado de maneira religiosa. ${ }^{14}$

Esta forma de experimentação da ética é aquilo que Benjamin compreende enquanto experiência de religiosidade. Ainda que subjetiva, nas suas mais diversas formas de apropriação e expressão, esta experiência é responsável por reunir a todos em torno de um propósito maior na luta pelo bem comum.

\footnotetext{
12 BOFF, 2001.

13 BENJAMIN, W. Reflexões sobre a criança, o brinquedo, a educação. São Paulo: Editora 34, 2002.

14 BENJAMIN, 2002, p. 15.
} 


\section{Religião e globalização}

No texto "Religião e Globalização", Enzo Pace ${ }^{15}$ apresenta uma compreensão do contexto atual, em que o mundo moderno se caracteriza por uma desterritorialização, uma dissolução das fronteiras simbólicas que separam as mais variadas culturas, o que leva à existência de um número cada vez maior de zonas francas enquanto espaços virtuais ou reais de contato com o Outro. Estas zonas apontam para uma tendência ao desenraizamento planetário, para uma perda de identidade, divulgando e operando um intercâmbio de diferentes culturas, e consequentemente, de diferentes religiões também.

Este intercâmbio religioso promovido pelo desaparecimento de fronteiras religiosas rígidas pode ser constatado pela crescente atenção recíproca e pelo esforço das religiões em falarem umas às outras, representando um aspecto característico das grandes religiões atualmente. Desta forma, dialogam entre si sobre os problemas que perpassam a espécie humana, tentando com isso se manterem atualizadas e adaptadas ao contexto de interdependência mundial ditado pela globalização. No debate realizado, a fala de alguns jovens contempla esta tendência das religiões contemporâneas:

Luciano: Eu conheço pessoas dentro da Igreja Metodista que têm uma visão ecumênica, as pessoas conversam com outros religiosos. Onde eu moro, tem um terreno de Candomblé e vai construir uma capela lá dentro. E tem também pastor evangélico da Igreja Presbiteriana, que é amigo da mãe de santo, a Yalaorixá. As pessoas, a gente está vendo o problema do Oriente Médio hoje, a gente vê essa coisa de aceitar o outro, que acho que é o exercício, assim, mais difícil, que envolve essa dimensão da religiosidade. Acho que é isso, essa dimensão da alteridade, aceitar o pensamento do outro que pensa diferente de mim, acho que isso é a coisa mais difícil mesmo.

\section{$(\ldots)$}

Rodrigo: Eu acho que existe uma troca entre religiões. Um exemplo assim é a música. Muitas músicas evangélicas são usadas na Igreja católica e vice-versa, têm coisas que eles trocam, é permitido com certeza.

Justamente por implicar num desenraizamento, o contexto do mundo globalizado exige e estimula que as nações adotem uma postura um tanto mais aberta para o Outro diferente, uma postura de não confiar mais totalmente no seu próprio sistema simbólico de interpretação do mundo, nas suas crenças, tanto políticas, como sociais ou religiosas, se dispondo a aprender com outras culturas. Durante o debate, Gabriel chamou a atenção para este fato.

15 PACE, E. Religião e globalização. In: ORO, A. P.; STEIL, C. A. Globalização e religião. Petrópolis: Vozes, 1997. 
Gabriel: Poder até mesmo aceitar, de repente incorporar, se existe algo de bom nesse pensamento do outro, incorporar isso no nosso sistema de crenças. $O$ problema é essa rigidez que há entre as religiões, dizendo: 'não essa aqui é a verdade, a palavra divina, vamos aceitar isso como verdade absoluta'.

O processo de globalização fez surgir duas tendências no cenário mundial, duas posturas possíveis a serem adotadas: a abertura à mestiçagem cultural, as forma híbridas, o que é a essência mesma dos sincretismos; ou o refúgio em universos simbólicos fechados, o que significa a busca das raízes representada pelos fundamentalismos, que mantém uma realidade social unida e coerente ao redor de si mesmos. Com isso, embora Gabriel tenha chamado a atenção para a rigidez que há entre as religiões, levando em conta a tendência aos fundamentalismos ainda existentes, as instituições religiosas em geral, mesmo as mais tradicionais, estão sendo levadas a se remodelarem para que possam se manter no "mercado religioso".

Deste modo, mesmo em face dos fundamentalismos religiosos ainda presentes, verifica-se de fato um diálogo inter-religioso que abre para formas menos rígidas e menos fechadas em si mesmas no contato com a dimensão religiosa. A desconstrução da ideia de uma verdade absoluta, para a acepção de uma liberdade que contempla a possibilidade de integração de diferentes crenças para se edificar uma fé individual e subjetiva, menos presa às tradições, são fatores determinantes para o enfraquecimento do poder das instituições sobre os indivíduos, dito desta forma por Enzo Pace: “em termos estritamente sociológicos tudo isso tem um nome. Chama-se processo de libertação religiosa: afastamento dos crentes das religiões institucionais ou frágil pertencimento (e identidade) do indivíduo às instituições religiosas "de origem" ${ }^{16}$ Essa necessidade atual verificada entre as religiões, de se remodelarem a fim de sobreviverem a este contexto plural, que acaba por punir os sistemas intransigentes e intolerantes, enclausurados em seus dogmas e suas verdades, pode ficar clara no seguinte depoimento:

Jessé: Eu tenho uma entrada muito forte no meio evangélico, e uma coisa que me chama atenção é que, é um exemplo só, mas é que para mim, me chama bastante atenção: no final de setembro, outubro, vai ter um congresso, acho que em Cabo Frio, o título é mais ou menos o seguinte "Congresso de solteiros, divorciados, desquitados evangélicos". Quer dizer, a pessoa um dia se casou, se divorciou e não saiu da religião, permanece enquanto evangélica e tem espaço para se discutir. Então o importante é atualizar a crítica dos dogmas.

Sobre as muitas consequências desta necessidade de adequação das religiões ao cenário contemporâneo, Pace afirma que há um esvaziamento que serve também para atender algumas demandas:

16 PACE, 1997, p. 34. 
Podemos dizer que agindo desta forma as grandes religiões se globalizam, banalizando as diferenças, até mesmo importantes que existem entre elas. Então, por que surpreender-se diante do fato de que aqueles que "consomem" as mensagens religiosas deste tipo, através dos meios de comunicação de massa, percebem cada vez menos os limites simbólicos entre diferentes, e às vezes antagônicos, sistemas de crença religiosa? ${ }^{17}$

O processo de globalização, retratado por Pace como esvaziador de importantes fundamentos religiosos, apareceu na fala de alguns jovens. Estes, a exemplo do autor, percebem o pluralismo religioso, expresso nos sincretismos que dão luz a novas maneiras de elaborar a fé que despontam no horizonte contemporâneo como perigoso. Segundo eles, em muitos casos este pluralismo pode acarretar num esvaziamento das premissas religiosas, sujeitas a se tornarem superficiais. Nesta perspectiva, toda esta engrenagem pós-moderna pode levar a uma falta de verdadeira implicação religiosa:

Késsia: Eu acho ótimo, assim, cada um vai buscar a sua maneira, do seu jeito, na sua vivência, um meio que acha mais adequado de ver o mundo. Assim como nós os psicólogos, cada um tem a sua linha que acha mais adequada ao seu cliente; enfim, meio que comparando muito mal, dá no mesmo, no sentido do quanto é rica essa diversidade toda. Eu só questiono um pouco a galera que faz meio que uma salada. Assim, teve um ali que falou que ao mesmo tempo vai em várias coisas diferentes: isso é um momento de conhecimento, de busca, ou é uma coisa comum? Tipo, eu acho muito legal, você falou que fez não é? Foi católico durante um tempo, está conhecendo uma outra religião. Acho ótimo também ter um conhecimento das outras, dos outros tipos de religião, até para saber porque que eu não me encaixo, porque que eu não gosto. Mas a salada de frutas é que eu não acho muito interessante não.

\section{$(\ldots)$}

Samara: Esse monte de religiões surgiu hoje em dia pelo modo como as pessoas interpretam a bíblia e a bíblia é feita de metáforas. Então quando o padre fala uma coisa vai para o cérebro de cada um do jeito que cada um entende. Uma vez eu li em algum lugar, e, nunca me esqueci dessa frase: 'o que estraga a fé das pessoas hoje em dia é essa divisão que tem quanto à religião'. Os evangélicos, por exemplo, gente eu fico doida com tanto tipo de Igreja que eles têm, é testemunha de Jeová, é Assembleia de Deus, é Presbiteriana, Batista. Eu tenho amigos dentro da Igreja Católica que desanimaram, começaram a frequentar os grupos, começaram a fazer catecismo, e hoje em dia eles não estão mais na Igreja que frequento. Acho que a quantidade de Igrejas confunde.

Em contraponto a esta visão de que o pluralismo religioso oferece o perigo de uma banalização do sagrado, Gabriel argumenta que o fato da diversidade de religiões existentes estarem à disposição para serem conhecidas e experimentadas por todos aqueles que assim desejarem, pode representar uma ótima oportunidade de se congregar

17 PACE, 1997, p. 38. 
aspectos oriundos de várias fontes numa fé subjetiva. Segundo ele, misturar diferentes crenças religiosas numa mesma fé, pode ser positivo, representando com isso a imersão num "caldeirão caótico" de onde pode surgir o novo:

Gabriel: Essa salada de fruta gera uma determinada caoticidade? Gera. Mas talvez, dê abertura, pro novo. É claro que acaba entrando num caldeirão meio caótico, mas eu acredito que dentro dessa caoticidade, acaba saindo uma ordem, acaba saindo um determinado sistema, uma determinada teologia, que talvez possa ser tanto mais aberta e mais interessante.

Frequentar diferentes religiões surge neste caso como possibilidade de experiência e conhecimento capaz de expandir o horizonte religioso para além de um único enquadre perceptivo, desvendando outras tonalidades possíveis, mesmo que esse movimento nem sempre seja fácil, o que fica claro no seguinte depoimento:

Luisa: Eu já visitei várias religiões, não porque eu me rebelei de ir contra a minha religião, fui conhecer porque amigas me chamaram. Ia a um culto, por exemplo, na Igreja Presbiteriana, que eu acho uma Igreja super legal, que tem uma doutrina bem parecida com a católica; já fui no centro espírita, no Kardecista e no Umbanda e eu achei muito legal, eu gostei do que eles falaram. Então, às vezes eu entro em conflito por acreditar numa coisa de outra religião, mesmo sendo católica, e isso forma uma coisa dentro de mim como se eu estivesse me revoltando contra a minha própria religião.

Ainda neste enfoque da diversidade religiosa, outro aspecto que surgiu nos debates foi a questão do uso das mídias na divulgação e difusão das religiões, dividindo opiniões sobre ser boa ou não a visibilidade dada às diversas manifestações religiosas que conseguem atingir um número muito maior de pessoas:

Luisa: Eu acho bom porque, por exemplo, eu não fui à missa no domingo, mas pude assistir à programação nova da Rede Vida.

\section{$(\ldots)$}

Rodrigo: Eu acho que a mídia espalha a palavra de deus para onde for, para qualquer lugar.

\section{$(\ldots)$}

Marina: Muitas das religiões que usam da mídia para propagar a fé, não estão pensando 'olha estou levando a palavra de deus para dentro da casa das pessoas e de alguma forma fazendo o bem para elas'. Não, na verdade preocupam-se em mostrar a sua religião, em divulgar o seu produto. 
Percebemos, a partir destes depoimentos, que se para uns a mídia representa um aspecto facilitador de divulgação da fé, para outros, como fica claro na fala da Marina, favorece uma maior circulação da religião como mercadoria, que visa não propriamente o bem de seus destinatários, mas tão só a satisfação dos interesses particulares das formas de poder assumidas. Do mesmo modo que esta jovem percebe a mídia enquanto mecanismo utilizado por uns como forma de impor uma religião para um grande número de pessoas, algumas manifestações religiosas, mesmo fora do espaço da mídia, são também tidas como invasivas e impositivas por outra jovem:

Samara: Várias vezes quando vou para casa de trem, da Central até Saracuruna vai um cara berrando no meu ouvido 'você tem que aceitar Jesus'. Então começa um monte de mulheres a cantar umas músicas; não gosto porque eles estão te impondo aquilo e tudo que chega ao campo do fanatismo para mim não é válido, não é fé. Você está dentro do trem, ali podem ter pessoas que são da Umbanda, do espiritismo, que são católicas, e tem um cara lá berrando da hora que você entra à hora em que você sai. Às vezes quero ler uma coisa, não consigo, porque estão querendo me impor uma religião.

Verificamos, a partir da análise de todos estes diálogos, o quão complexo é o apelo provocado pela atual diversidade religiosa. De um lado, instiga os fundamentalismos a manterem um extremo fechamento, mais preocupados ainda em preservar suas crenças a todo custo, evitando ao máximo uma exposição que possa lhes custar um afastamento de suas verdades e um prejuízo cultural. E, quanto ao caso dos sincretismos religiosos, cada vez mais frequentes num contexto de mundo globalizado em que todos são convidados a se abrir para o diferente, pagam o preço, muitas vezes caro, do risco de expor as suas premissas, incorrendo na possibilidade de que sejam esvaziadas. Esses são os dois polos que marcam os extremos de uma inumerável gama de possíveis implicações que toda esta diversidade provoca no campo das religiões.

A partir disto, refletimos que se por um lado este contexto aponta para um esvaziamento das religiões, que apressadas em dialogar deixam para trás importantes aspectos constitutivos, afastando-se de suas raízes, convoca também para uma tolerância maior com as diferenças, aproximando-as e colocando-as em diálogo. Isso significa dizer que tal diversidade acompanhada de um maior contato inter-religioso pode ser profícua em termos políticos, muito embora no que diz respeito ao aspecto espiritual venha a implicar numa descentralização de questões outrora muito bem sistematizadas no bojo de um regime mais protegido das intempéries do contexto global, que muitas vezes tritura importantes signos culturais.

\section{Considerações finais}

Este trabalho buscou compreender as diversas formas de elaboração e expressão do religioso entre os jovens contemporâneos. Assim, foram realizadas "oficinas de debate" 
com 16 jovens universitários entre 18 e 29 anos. Seus depoimentos foram apresentados e discutidos à luz do instrumental teórico. A partir das muitas questões discutidas, concluise que o momento histórico aponta numa direção que, ao que tudo indica, representa uma profunda e importante transformação das formas religiosas antigas para uma nova maneira de experimentação da fé. Não conseguimos, contudo, vislumbrar esse movimento em toda a sua extensão e dimensão, pois ainda está se configurando num processo de que só mais tarde poderemos obter maior compreensão.

Entretanto, foi possível perceber que os discursos dos jovens caminharam no sentido de afirmar certa independência entre a noção de religião e a noção de espiritualidade, sendo esta última representante de uma experiência de transcendência que não necessariamente depende da mediação institucional. No que se refere ao discurso religioso, o contexto de globalização acaba produzindo dois movimentos: extremo fechamento das religiões como estratégia para proteção de seus dogmas ou, por outro lado, a abertura de espaços ao sincretismo advindo deste encontro. Assim, entendemos que os jovens possuem uma responsabilidade relevante na discussão acerca da religiosidade humana pois, são os que recebem a cultura religiosa acumulada historicamente, mas que também detém o poder de criar um modo específico de diálogo com esse discurso, ampliando-o.

Com esta pesquisa, percebemos ainda que o tema da religiosidade não é inexistente ou distante dos jovens, pois, pelo contrário, havia muito a ser expresso acerca dessa dimensão durante as oficinas. O que podemos concluir é que há um modo outro de estar conectado com o discurso religioso, mais aberto aos questionamentos, e, talvez, mais centrado na fé e na experiência espiritual como núcleo da relação do humano com o religioso. As instituições e as religiões, ainda que permaneçam como mediadores fundamentais, parecem deixar o centro para serem parte da relação destes jovens com o sagrado.

\section{Referências}

BAKHTIN, M. Estética da criação verbal. São Paulo: Martins Fontes, 1992.

BENJAMIN, W. Reflexões sobre a criança, o brinquedo, a educação. São Paulo: Editora 34, 2002.

BERGER, P. O dossel sagrado. São Paulo: Paulinas, 1985.

BOFF, L. Espiritualidade: um caminho de transformação. Rio de Janeiro: Sextante, 2001.

GODINHO, D. M. da S. Paradigmas do religioso entre os jovens contemporâneos. Monografia (Trabalho de Conclusão de Curso) - Departamento de Psicologia, Rio de Janeiro, Pontifícia Universidade Católica do Rio de Janeiro, 2007. 
GODINHO, D. M. da S; CARVALHO, C. de S.; JOBIM e SOUZA, S. Experiências Religiosas da Juventude Contemporânea: indagações sobre fé, secularização, ética e política. Psicologia Política, v. 14, n. 29, p. 137-150, 2014.

PACE, E. Religião e globalização. In: ORO, A. P.; STEIL, C. A. Globalização e Religião. Petrópolis: Vozes, 1997.

VERNANT, J. P. Para que servem as religiões. Religião e Sociedade, v. 9, p. 65-70, 1983. 